\title{
Surveillance colonoscopy following resection of colorectal polyps and cancer
}

\author{
Douglas K Rex MD
}

DK Rex. Surveillance colonoscopy following resection of colorectal polyps and cancer. Can J Gastroenterol 2001; 15(1):57-59. Patients undergoing clearing colonoscopy with resection of adenomas should generally have their next examination at three years. Exceptions include large sessile adenomas removed piecemeal (re-examine at two to six months until no evidence of recurrent polyp, then at one year), average risk patients with a single tubular adenoma (next examination at five years) and patients with 'numerous' adenomas (next examination at one or two years).

Patients with surgically resected colorectal cancer should have a clearing colonoscopy preoperatively or within two to three months of surgery in obstructed patients, even if the preoperative barium enema is negative for proximal lesions. After the clearing colonoscopy, subsequent examinations can be performed based on the associated adenoma findings.

Key Words: Adenomas; Colonoscopy; Colorectal cancer; Colorectal polyps

\section{Coloscopie de contrôle à la suite de la résection de tumeurs cancéreuses ou de polypes colorectaux}

Les patients qui subissent une coloscopie exploratoire avec résection d'adénomes devraient généralement être soumis à un examen de contrôle au bout de trois ans. Il y a toutefois certaines exceptions : les résections parcellaires d'adénomes sessiles volumineux (examen de contrôle aux deux à six mois jusqu'à l'absence objective de réapparition de polypes, puis un an plus tard), les résections d'un adénome tubuleux unique chez les patients à risque moyen (examen de contrôle dans cinq ans) et les résection d'adénomes multiples (examen de contrôle dans un an ou deux). Les patients opérés pour un cancer colorectal devraient subir une coloscopie exploratoire en phase préopératoire ou de deux à trois mois avant l'intervention chez les patients présentant une occlusion, et ce, même si le lavement baryté en phase préopératoire s'avère négatif pour les lésions proximales. Après la coloscopie exploratoire, les examens de contrôle devraient être pratiqués en fonction des résultats d'analyse des adénomes.
Cose rolonic polypectomy is one of the most powerful tools used in clinical medicine. There is really no other organ system where cancer mortality can almost be completely prevented by an examination that does not disturb the anatomy or function of the organ. In nine studies involving more than 3000 patients with colonic adenomas who underwent clearing colonoscopy and then follow-up surveillance (including the National Polyp Study and the
Funen Adenoma Follow-up Study), there have been 19 incident colorectal cancers, but only one death from colorectal cancer (1).

\section{POSTPOLYPECTOMY SURVEILLANCE}

The principal study that guides postpolypectomy surveillance is the National Polyp Study (2). The National Polyp Study was a randomized, controlled trial in which patients

This mini-review was prepared from a presentation made at the American Congress of Gastroenterology, Boston, Massachusetts, October 9 to 14,1998

Indiana University School of Medicine, Indiana University Hospital, Indianapolis, Indiana, USA

Correspondence and reprints: Dr Douglas K Rex, Indiana University School of Medicine, 550 North University Boulevard, Room 2300, Indianapolis, Indiana 46202, USA. Telephone 317-274-0912, fax 317-2740-0975

Received for publication November 20, 1998. Accepted November 28, 1998 
who had undergone clearing colonoscopy were randomly assigned to receive colonoscopy at one year and three years, compared with three years only. Patients with malignant polyps or with sessile adenomas larger than $3 \mathrm{~cm}$ were excluded from the study. The primary end point of the study was the occurrence of advanced adenomas at follow-up. An advanced adenoma was defined as one with severe ('high grade') dysplasia or invasive cancer. The principal finding of the study was that the incidence of advanced adenomas was equivalent in the two study arms at $3 \%$. Thus, it was concluded that most patients could have their first followup colonoscopy three years after clearing colonoscopy.

It should be noted that the National Polyp Study is very much a miss rate study. Patients in the arm that received two colonoscopies were more likely to have an adenoma detected (42\% compared with $32 \%$ ) and had a total of about $40 \%$ more adenomas than the group that had only one colonoscopy. Thus, because the randomization was effective, one can conclude that the miss rate for adenomas in the National Polyp Study was approximately $40 \%$. This miss rate is, in fact, higher than the miss rate for adenomas seen in two tandem colonoscopy studies in which patients underwent colonoscopy twice in the same day $(3,4)$. The inescapable conclusion is that, while colonoscopy has a substantial miss rate for small polyps, including small adenomas, this miss rate has almost no bearing on its effectiveness in reducing mortality from colorectal cancer.

The new colorectal cancer screening benefit for American Medicare beneficiaries includes patients with previous adenomas among those in the 'high risk' group. The Medicare benefit allows payment for colonoscopy at an interval of every two years in patients with previous adenomas or cancer. In fact, essentially all society guidelines had already been changed to recommend three-year intervals after polypectomy or after clearing colonoscopy in cancer patients by the time the Medicare benefit was written. Certainly it is important that clinicians perform colonoscopy in most patients at three-year intervals rather then the two-year intervals that are covered in the American Medicare benefit.

There are situations in which deviation from the threeyear interval is clinically appropriate. The most important situation is that of the patient with a large sessile polyp, particularly one that is removed in a piecemeal fashion. As noted above, patients with sessile adenomas larger than $3 \mathrm{~cm}$ in size were excluded from the National Polyp Study. In fact, large sessile adenomas are the most dangerous colon polyps encountered in clinical practice. They are more likely to contain invasive cancer, more likely to contain cancer associated with lymph node metastases and more likely to recur after apparent complete endoscopic resection than any other type of colon polyp (5). After apparent complete resection, such polyps should be followed-up at two- to sixmonth intervals. If there is apparent residual tissue, it should be removed, preferably by snare polypectomy or obliterated by electrocoagulation after biopsy. The recurrence rate after removal of large sessile polyps is $16 \%$ to
$28 \%$. In addition, a significant number of recurrences can develop one year after complete resection. Therefore, even after apparent complete resection has been verified, it may be best to perform the next colonoscopy in one year.

Another situation in which deviation from the threeyear interval is appropriate is a patient with 'numerous' adenomas. In multiple studies, multiplicity of adenomas has been a predictor of advanced adenomas at follow-up. In the National Polyp Study, the most important predictor of an advanced adenoma during follow-up was the presence of three or more adenomas at the index clearing colonoscopy. The guideline published by the Agency for Healthcare Policy and Research (6) states that it is still appropriate to perform a colonoscopy at one year in a patient with 'numerous' adenomas. Obviously, this leaves the definition of 'numerous' up to the clinician's judgment. In my own practice, fewer adenomas would be required to stimulate an examination at one or two years if one or more is larger than $1 \mathrm{~cm}$.

Another potential exception to the three-year rule is the patient with only a single tubular adenoma less than $1 \mathrm{~cm}$ in size. The chance that such a patient will have an advanced adenoma at follow-up colonoscopy at three years appears to be less than $1 \%$ (2). It would seem reasonable in such patients to expand the interval to five years, although direct observational data from the National Polyp Study, which thus far have only been abstracted (7), show that a family history of colorectal cancer, particularly in a person older than 60 years of age, was another predictor of advanced ademonas at first follow-up. Therefore, it is not my own practice to extend the follow-up interval to five years in patients with single tubular adenomas who also have a family history of colorectal neoplasia, but rather to maintain the interval at three years in those patients.

\section{POSTCANCER RESECTION}

It should be noted that follow-up of colon cancer is directed toward identifying metachronous lesions. This is particularly true above the rectum, where the anastomotic recurrence rate is only $2 \%$ to $3 \%$ (1), and most anastomotic recurrences signal intra-abdominal recurrences that are unresectable for cure. The anastomotic recurrence rate in the rectum is around $10 \%$ and varies with surgical technique, but still there is no clear evidence that regular follow-up by flexible sigmoidoscopy can improve the survival rate. Additional study is needed to determine whether regular examination that includes endoscopic ultrasound can increase the identification of surgically curable rectal recurrences. The most important examination for patients with colon cancer is the colonoscopy that clears the colon of synchronous disease. If this cannot be performed preoperatively because of obstruction, it should be performed two to three months after surgery, even if a preoperative barium enema revealed no synchronous disease proximal to the tumour. Once the colon has been cleared, repeating colonoscopy at three- to five-year intervals is adequate (8), or according to the associated adenoma findings. An exception is patients with hereditary nonpolyposis colorectal 
cancer, who should be treated with subtotal colectomy followed by annual endoscopy of the rectum for the remainder of their lives.

\section{REFERENCES}

1. Rex DK. Colonoscopy: a review of its yield for cancers and adenomas by indication. Am J Gastroenterol 1997;90:353-65.

2. Winawer SJ, Zauber AG, O’Brien MJ, et al. Randomized comparison of surveillance intervals after colonoscopic removal of newly diagnosed adenomatous polyps. N Engl J Med 1993;328:901-6.

3. Rex DK, Cutler CS, Lemmel GT, et al. Colonoscopic miss rates of adenomas determined by back-to-back colonoscopies. Gastroenterology 1997;112:24-8.
4. Hixson LS, Fennerty MB, Sampliner RE, McGee D, Garewal H. Prospective study of the frequency and size distribution of polyps missed by colonoscopy. J Natl Cancer lnst 1990;82:1769-72.

5. Walsh RM, Ackroyd FW, Shellito PC. Endoscopic resection of large sessile colorectal polyps. Gastrointest Endosc 1992;38:303-9.

6. Winawer SHJ, Fietcher RH, Miller L, et al. Colorectal cancer screening; clinical guidelines and rationale. Gastroenterology 1997;112:594-642.

7. Winawer SJ. Appropriate intervals for surveillance. Gastrointest Endosc 1999;49:563-6.

8. Schoemaker D, Bloack R, Giles L, Toouli J. Yearly colonoscopy, liver CT, and chest radiography do not influence 5 -year survival of colorectal cancer patients. Gastroenterology 1998:114:7014. 


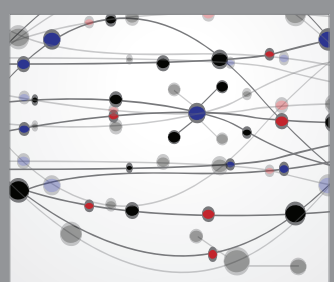

The Scientific World Journal
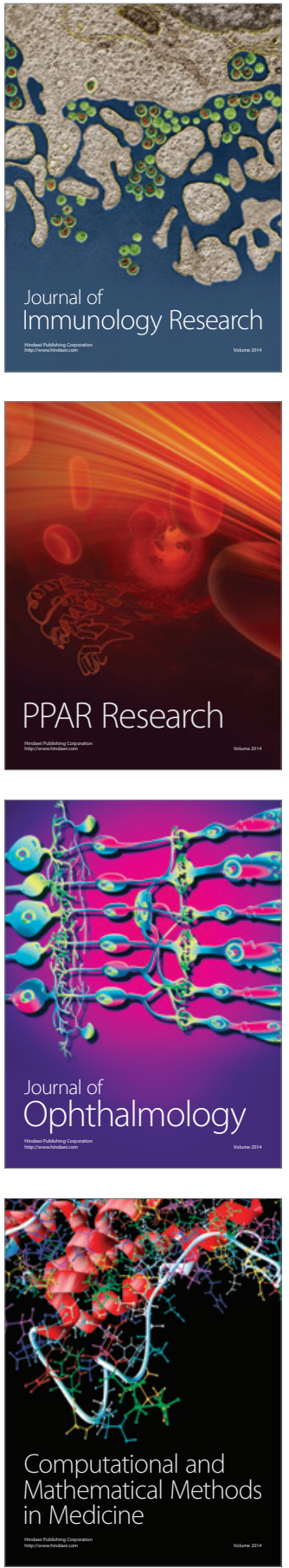

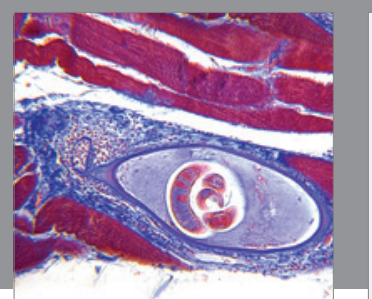

Gastroenterology Research and Practice

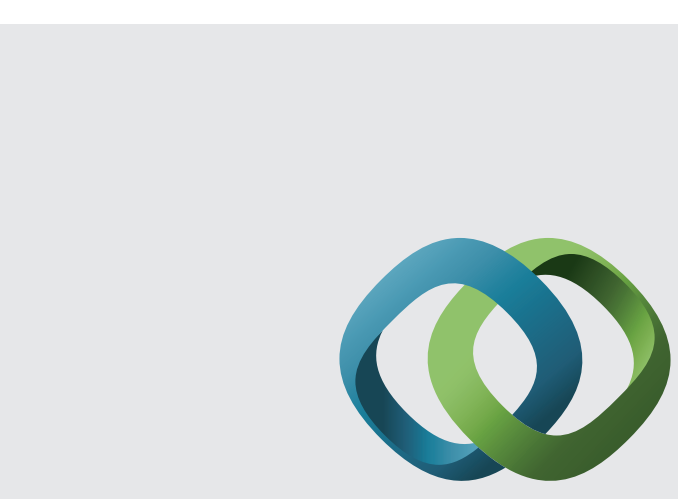

\section{Hindawi}

Submit your manuscripts at

http://www.hindawi.com
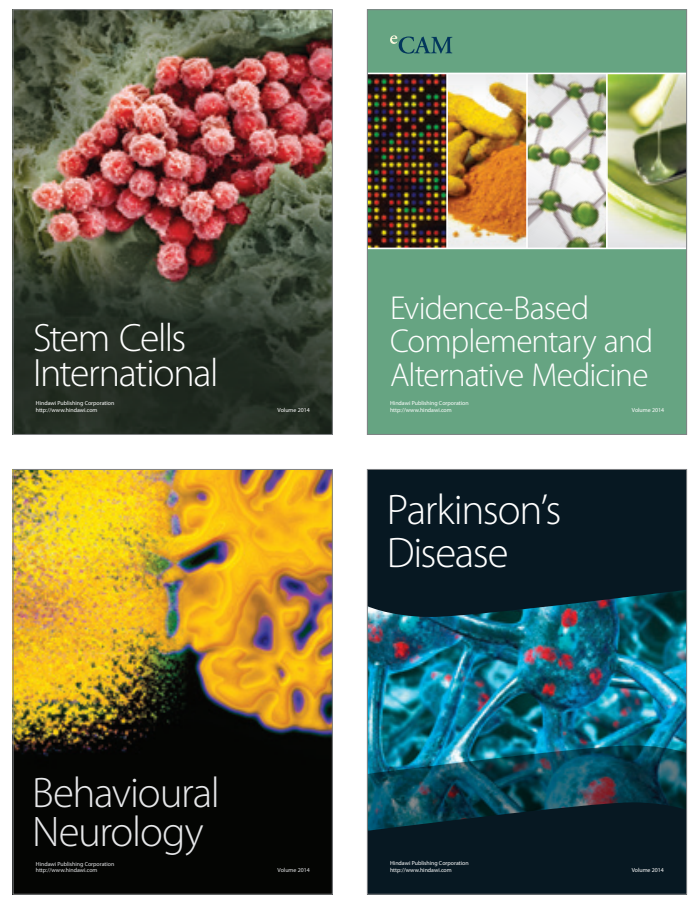
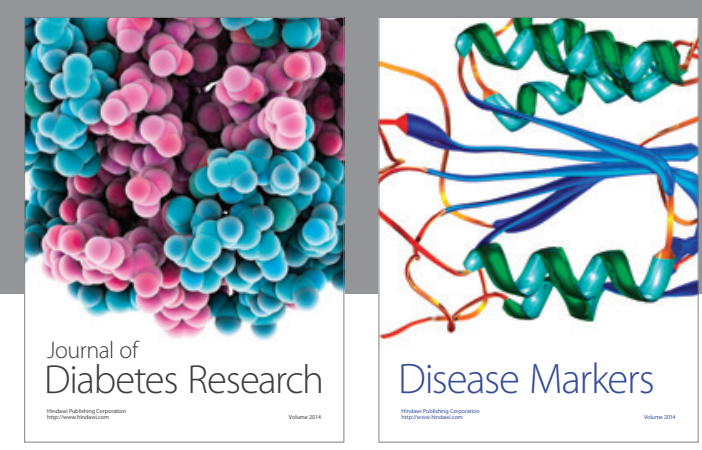

Disease Markers
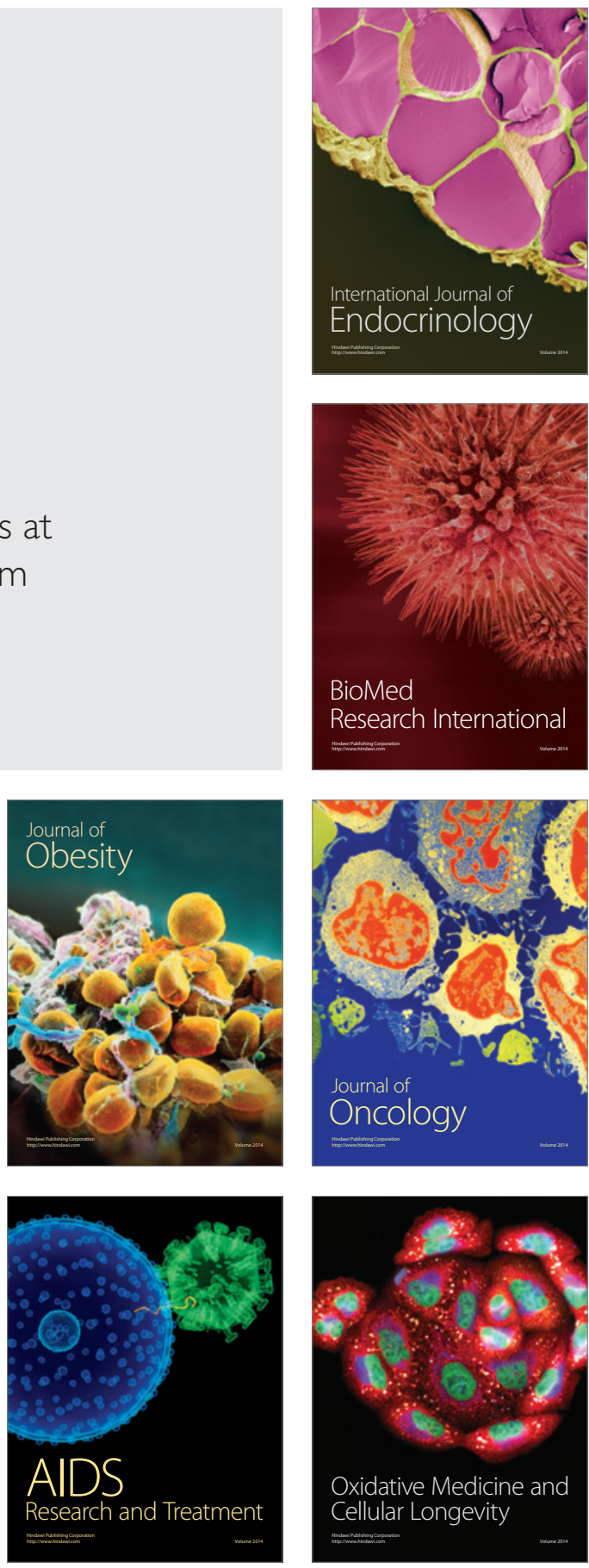